\title{
GROUP A HEMOLYTIC STREPTOCOCCUS ANTIBODIES. I. GRIFFITH TYPE AGGLUTININ AND ANTISTREPTOLYSIN TITERS IN NORMAL MEN AND IN ACUTE INFECTIONS
}

\author{
By LOWELL A. RANTZ, WILLIAM M. M. KIRBY, AND ALVIN H. JACOBS \\ (From the Departments of Medicine and Pediatrics, Stanford University \\ School of Medicine, San Francisco)
}

(Received for publication November 5, 1942)

The immunological phenomena associated with various aspects of hemolytic streptococcus disease in man have usually been studied by the measurement of antitoxins. Most extensive have been the observations made by the Dick technique (1), in which purified erythrogenic toxin was used as a skin test material. Circulating antistreptolysin and antifibrinolysin titers have also been determined, particularly in individuals suffering from glomerulonephritis and rheumatic fever (2).

The measurement of antibacterial antibodies has been less satisfactory. Phagocytosis (3) and the destruction of the living organism by whole blood (4) have been the most recent methods of choice.

The agglutination of hemolytic streptococci by human serum has also been frequently studied (5). Many attempts were made during the first two decades of this century to establish the etiological relationship between streptococci and scarlet fever and many other diseases by the application of agglutination tests, using as antigens streptococci isolated from various sources. Usually, it was demonstrated that the convalescent serum of individuals suffering from infectious processes, now known to be caused by the hemolytic streptococcus, had higher titers of agglutinins than had controls, but the difficulties inherent in the production of stable antigens and the many confusing cross reactions caused a nearly complete abandonment of the phenomenon of agglutination as a means of study of streptococcus disease.

Much more recently several studies have been made of the hemolytic streptococcus agglutinin content of the sera of individuals suffering from various forms of arthritis, which have indicated that increased amounts of these antibodies are present in association with the rheumatoid type (6). The variations from the normal have not been sufficiently great to permit the use of the agglutination test in the diagnosis of disease of the joints, nor to establish definitely the role of the streptococcus in the causation of rheumatoid arthritis.

One group has described the agglutination of hemolytic streptococci by high dilutions of serum obtained from febrile patients known not to be suffering from streptococcus infections (7).

It has been recently demonstrated that nearly all serious human infections, particularly those involving the respiratory passages, are caused by hemolytic streptococci serologically homogenous, the members of the Lancefield Group A (8). By the application of a technique of slide agglutination, more than 20 types have been identified within this group (9). Antibacterial immunity to infection with organisms of Group A, like that of the pneumococci, has been shown to be largely type specific (10). It is apparent, therefore, that the satisfactory study of the agglutinin content of human sera for the hemolytic streptococci pathogenic for man must be conducted in such a way that antigens made from strains of many types may be used. This can easily be accomplished by the application of a slide technique, first described by Ozaki (11), who, using antigens of all of the Griffith types, found that each was agglutinated by a small number of normal sera. Later, other Japanese workers (12) studied acute and convalescent sera obtained from individuals ill with scarlet fever. They also demonstrated that agglutinins for many types were present and that 39 per cent showed a definite increase in the amount of antibody for the homologous type of streptococcus during convalescence. Walker (13) also studied the development of agglutinins in scarlet fever by the slide method and showed that these antibodies appeared in approximately 25 per cent of all cases and that they were type specific. 
In this study, the agglutinins present in normal sera have been measured by a slide technique, as has the agglutinin response to acute infection with the hemolytic streptococcus. Both have been compared with antitoxic immunity by means of antistreptolysin determination.

\section{MATERIALS AND METHODS}

Sera

All bloods were collected by venipuncture and the sera removed from the clots in the usual manner and stored at $5^{\circ} \mathrm{C}$. in the cold room. All sera were inactivated at $56^{\circ} \mathrm{C}$. for 30 minutes and the antistreptolysin titers determined before the agglutination tests were performed.

a. Preparation of antigens. Antigens for the slide agglutination tests were prepared and the tests performed in the same manner as has been previously described (14), using standard type specific strains of Group A hemolytic streptococci, obtained from the Lederle Laboratories. Many sera were tested against antigens of Types 1, 2, 4, $6,9,11,12,13$, and 25 .

Frequently an antigen was prepared from an organism isolated from the individual under study and used in the tests. It proved to be much more satisfactory to use antigens of the same type, prepared from stock strains which were known to give smooth, stable suspensions if the homologous organism could be identified serologically. Satisfactory antigens could be prepared only if the organism was grown very slowly. Incubation at ordinary room temperatures in a rotating box usually gave excellent conditions for this purpose, but it was noted that marked granularity and instability developed in antigens incubated on very warm days.

If these precautions failed to induce the development of sufficiently smooth suspensions, a drop of 10 per cent trypsin solution was added to the thick agglutinating suspension and the whole was incubated at $37^{\circ} \mathrm{C}$. for approximately 15 minutes. This procedure was invariably followed by the development of a stable but somewhat insensitive antigen. It should be emphasized that suspensions of streptococci quite satisfactory for Griffith typing may well be too unstable for use in the testing of human sera and false positive reactions will be obtained.

A stable, diffuse antigen having been obtained, it was found to remain in a satisfactory state for many months if the living culture was stored at $5^{\circ} \mathrm{C}$. in the refrigerator when not in use. No preservative was added. Each time tests were to be made the antigens were checked with known negative and positive sera. The latter were diluted to three-fourths of their agglutinin titer. This precaution was especially important if any of the antigens contained trypsin.

b. Preparation of sera. The heated human sera were first tested against the various Group A type specific antigens by means of slide agglutination tests in the undiluted state. Further tests were then performed with saline di- luted serum against those types showing clumping in one minute or less.

All agglutinin titers in this and the following report are described in terms of the actual dilution of the serum used in the tests. In the slide test, a small drop of serum was mixed with a large drop of antigen suspension, so the actual dilution titers were, therefore, from 2 to 4 times greater than those presented in these reports.

\section{Antistreptolysin titers}

The antistreptolysin titer of each serum was determined by the method described by Coburn and Pauli (15), who were kind enough to supply lyophilized cultures of the Aronson strain of streptococcus and generous amounts of standard human sera.

\section{Throat culture}

Swabs were carefully rubbed over the posterior pharynx and in both tonsillar fossae. Cultures were prepared and serological classification of the isolated hemolytic streptococci was performed using the techniques previously described $(14,16)$.

\section{PROCEDURE AND RESULTS}

\section{Normal individuals}

The sera of 47 normal, healthy, male, medical students were studied to determine the presence of agglutinins for Group A streptococci of Types $1,2,4,6,9,11,12,13$, and 25 , which were responsible for 60 to 75 per cent of all instances of infection in the San Francisco area during the two previous years. The antistreptolysin titer of each serum was also measured.

Throat cultures were obtained from each of the studied individuals, all of whom had undergone previous tonsillectomy more than one year previously. None harbored Group A hemolytic streptococci in the naso-pharynx. The results of study of carriers of these organisms will be presented in the following paper.

Results. Figure 1 summarizes the serological observations on these 47 normal subjects. The highest agglutinin titer for any of the 9 types of streptococcus obtained with each serum and the antistreptolysin titer was used to construct the figure. Of the sera, 53.2 per cent contained no agglutinins for the studied Group A hemolytic streptococci and 21.2 per cent had demonstrable agglutinins only when the undiluted serum was used in the tests. The agglutinin titer was $1: 4$, or more, in 25.6 per cent. 


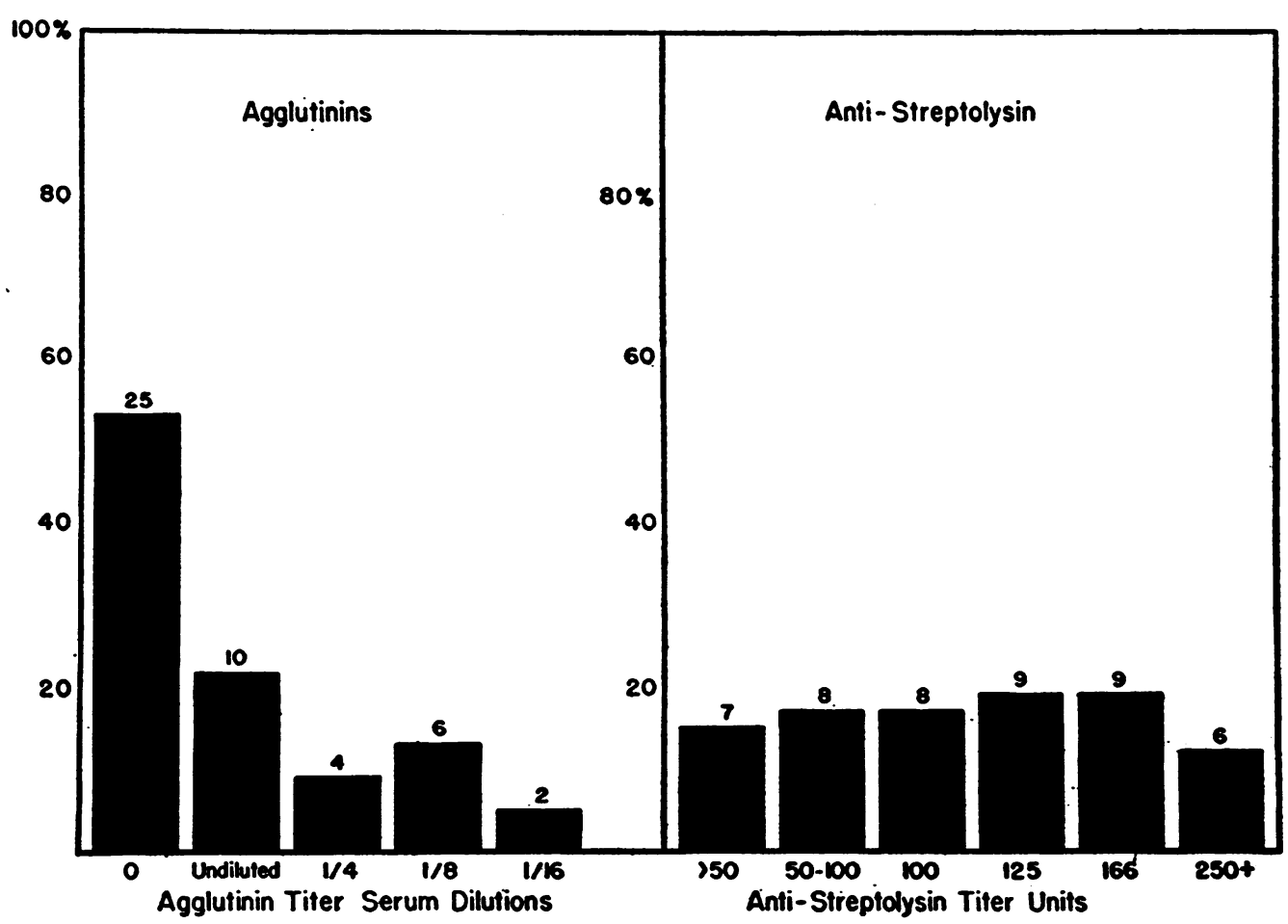

Fig. 1. Hemolytic Streptococcus Agglutinin and Anti-Streptolysin Titers in 47 Normal Medical Students

Figures above columns refer to the number of men in each group.

The types agglutinated and the titers of the sera for each type are presented in Table I. Twentytwo positive sera agglutinated 33 antigens, since some sera caused the agglutination of more than one type. Similar cross reactions will be discussed later. Agglutinins for Types 1, 9, 12, and 13 were not discovered in any serum, and antibodies for Types 2, 6, and 25 were most frequently present. The antistreptolysin titers of 31.9 per cent of the serums obtained from these normal individuals were greater than 125 units, but only 12.7 per cent were above 166 units.

TABLE I

Types of group $A$ streptococci agglutinated by the sera of normal medical students

\begin{tabular}{c|c|c|c|c|c|c|c|c|c}
\hline & \multicolumn{7}{|c}{ Griffith types } \\
\cline { 2 - 7 } & 1 & 2 & 4 & 6 & 9 & 11 & 12 & 13 & 25 \\
\hline Unditers & & 5 & 3 & 5 & & 1 & & & 3 \\
$1: 4$ & & 2 & 1 & 2 & & 1 & & & 1 \\
$1: 8$ & 3 & & & & 1 & & & 2 \\
$1: 16$ & 1 & & 1 & & 3 & & & 7 \\
Totals & 11 & 4 & 8 & & 3 & & & 7 \\
\hline
\end{tabular}

Very careful histories were obtained from these subjects in relation to previous infections with the hemolytic streptococcus, such as scarlet fever and/ or repeated attacks of tonsillitis. In 24 instances, it was probable that such infections had not occurred, whereas in 15, a definite past history of streptococcus disease was obtained. Four were doubtful and 4 were arbitrarily placed in the previously infected group because, at the time of this study, the antistreptolysin titers of the sera of these men were greater than 250 units.

A study of the agglutinin titers in relation to this division of cases is of interest. Only 8 per cent of the sera obtained from individuals with a negative past history had agglutinin titers of $1: 4$ or more, and two-thirds contained no agglutinins at all. Of those with a past history of hemolytic streptococcus infection, or who had a markedly elevated antistreptolysin level, agglutinin titers of $1: 4$ or more were found in 47.5 per cent and only 42 per cent had no agglutinins.

A scatter graph was constructed to determine the relation of the agglutinin to antistreptolysin 
titers but has not been presented since no definite correlation between the two values was discovered.

\section{Acute infections}

The agglutinin and antistreptolysin response during acute infection by the Group A hemolytic streptococcus was determined by the frequent measurement of these antibodies during the course of 24 cases of typical scarlet fever, studied from the first through the third or fourth week of the disease. Twenty-two of the infected individuals were children under the age of 14 years, and 2 were adults. Only one suffered a suppurative complication in the form of an otitis media. Fifteen received full doses of a sulfonamide early in the course of the disease.

Agglutinin response. Agglutinins for the homologous type of streptococcus developed in 13 of the 24 cases in whom these antibodies were not present at the onset of the disease. In two cases, the serum contained type specific agglutinins on the fourth and sixth days, respectively. In one
TABLE II

The relation of the Griffith type of infecting streptococcus to the maximum agglutinin titer for the homologous type in 22 cases of scarlet fever

\begin{tabular}{|c|c|c|c|c|c|c|c|c|c|}
\hline \multirow{2}{*}{$\underset{\text { titer }}{\text { Maximum }}$} & \multicolumn{8}{|c|}{ Griffith types } & \multirow{2}{*}{ Total } \\
\hline & 2 & 3 & 4 & 6 & 11 & 23 & 25 & $\begin{array}{c}\text { Uniden- } \\
\text { tified, }\end{array}$ & \\
\hline $\begin{array}{c}\text { Negative } \\
\text { Undiluted } \\
1: 4 \\
1: 8 \\
1: 16 \\
1: 32\end{array}$ & 1 & 1 & 1 & $\begin{array}{l}1 \\
1 \\
2\end{array}$ & $\begin{array}{l}5 \\
1 \\
\\
2\end{array}$ & & $\begin{array}{l}1 \\
1 \\
2\end{array}$ & 2 & $\begin{array}{l}9 \\
1 \\
2 \\
3 \\
5 \\
2\end{array}$ \\
\hline
\end{tabular}

of these, the dilution titer was greater than $1: 16$, in the other, it was not measured.

When an agglutinin response occurred, the level of circulating antibody usually increased sharply during the sixteenth to twentieth day after the onset of the infection and at a time when convalescence was well established. In two instances, elevated titers appeared on about the twelfth day. These relationships are summarized in Figure 2.

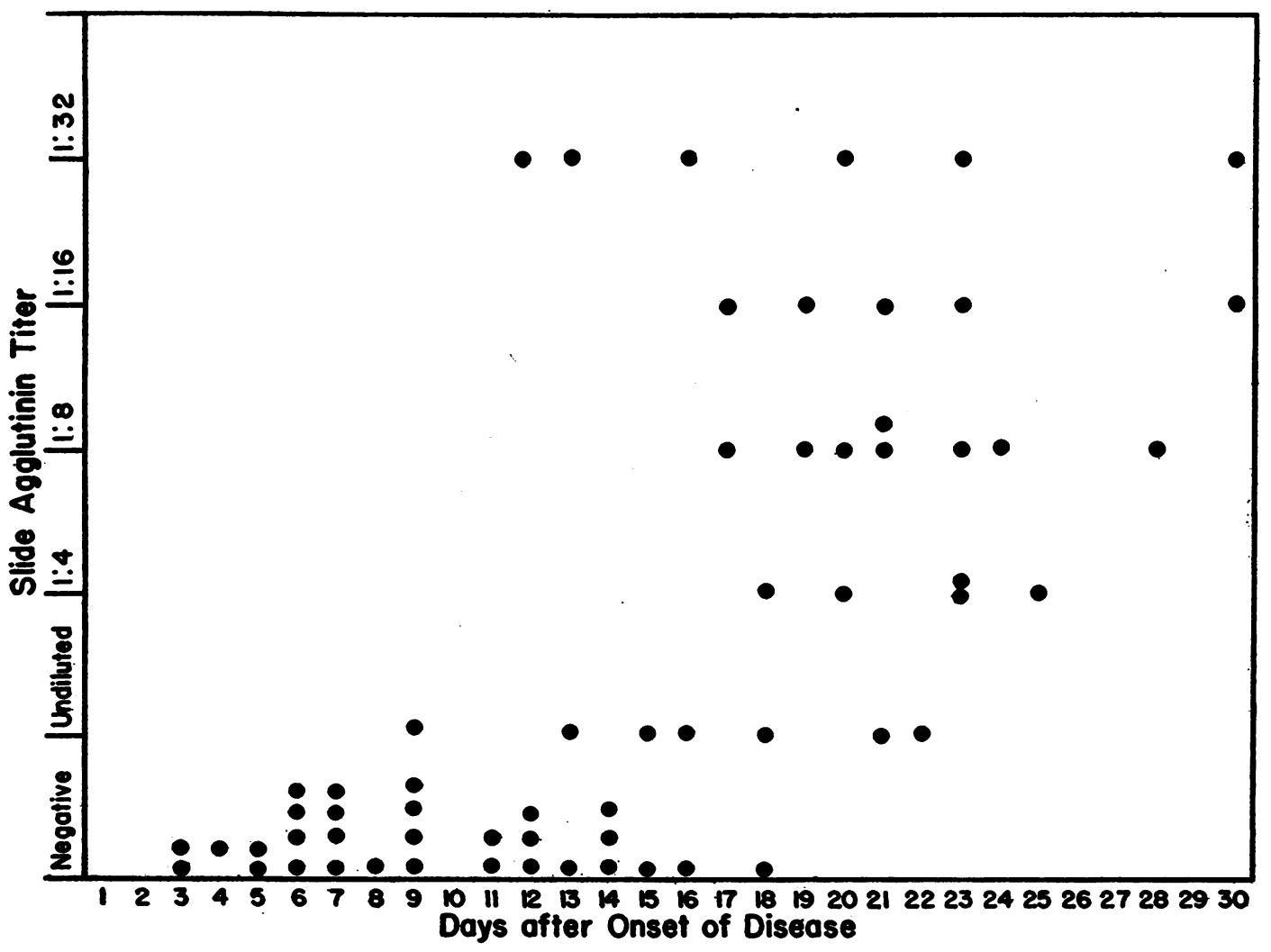

Fig. 2. Agglutinin Response in 13 Scarlet Fever Patients 


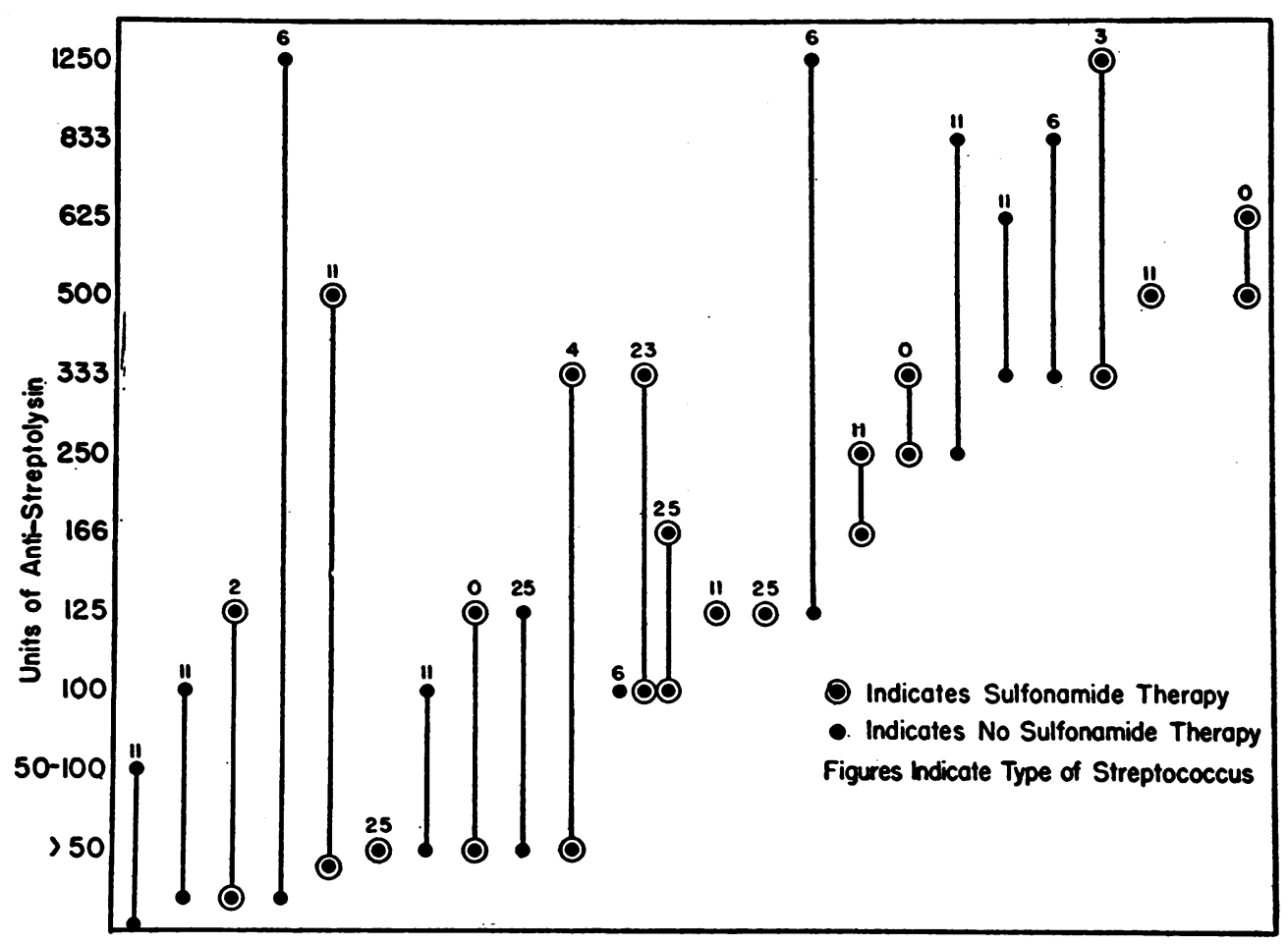

Fig. 3. Maximum and Minimum Antistreptolysin Titers in 24 Cases of Scarlet Fever

In Table II, the maximum agglutinin titer for the homologous organism is compared with the type of infecting streptococcus.

A cursory examination of these data indicates that Type 11 failed to stimulate an agglutinin response much more frequently than the other types. A more critical analysis reveals that this effect may have been due to the use of sulfonamides in the treatment of certain of these cases. Thus, only 6 of 13 , or 46.2 per cent, of drug-treated cases developed agglutinins, where 7 of 9 , or 77.8 per cent, of those not so treated did so. Furthermore, response occurred in 3 of 4 untreated Type 11 cases, but none was demonstrated in 4 who received a sulfonamide. Insufficient numbers of cases of the other types were observed to draw further conclusions as to the relationship between chemotherapy and the development of these antibodies.

Inter-type cross agglutination. In 9 instances, sera were examined for cross agglutination with other than the homologous organism, using antigens prepared from the 8 types previously used in the study of normal sera. In the following paper, the presence of high titers of agglutinins for Group
A streptococci in the sera of tonsillar carriers of these organisms will be described. Observations were made in these 33 cases for the presence of cross agglutination reactions as well. The results of the study of these 42 cases may well be presented at this time.

In 11 instances, no agglutinins for the homologous type were demonstrable. Antibodies were discovered in 6 of these, in titers greater than $1: 4$, for one or more of the other types. Cross agglutinins were not demonstrated in 9 of those individuals in whom homologous agglutinins were definitely present. Among the others, the heterologous agglutinin titer roughly paralleled the homologous, but was often higher.

The most frequent cross reactions were Type 6 with Type 2; Type 11 with Types 1 and 6; Type 12 with Types 6 and 2 ; and Type 25 with Type 2. It is interesting that in instances of infection with. Types 11 and 12, cross agglutinins for Type 6 usually were present, but when Type 6 was the infecting organism, agglutinins for the other two types were never found.

Antistreptolysin response. "An àntistreptolysin response to infection with the Group A strep- 
tococcus occurred in 19 of the 24 cases of scarlet fever that were studied. The increase in level of circulating antitoxin usually accompanied or preceded the agglutinin response and developed on the thirteenth to eighteenth days of the infection.

Four of the 5 patients in whom no antistreptolysin response occurred were treated with sulfonamides. It is of interest to note that the 5 individuals who did not form antistreptolysin also failed to develop agglutinins. In Figure 3, the initial and maximum antitoxin titers are presented. In the first week, they were greater than 250 units in 6 instances. It should also be noted that patients with low initial titers tend to have low maximum titers and the reverse, but that there are notable exceptions to this generalization. Correlation between the type of infecting streptococcus and the antistreptolysin response was not observed, but the 2 cases showing the most striking increase in titer were both due to organisms of Type 6.

\section{DISCUSSION}

These observations indicate that the measurement of hemolytic streptococcus agglutinins in human sera by means of a slide technique is a satisfactory procedure. Most important is the use of stable antigens, and methods for their preparation have been described.

A study of 47 normal young males, who were not carriers of Group A streptococci, using the antigens prepared from those types of these organisms most frequently the cause of disease in the San Francisco area, showed that approximately 47 per cent contained agglutinins for one or more types. In only 25 per cent, however, were the titers as great as $1: 4$. Such levels were present in only 8 per cent of individuals with no past history of hemolytic streptococcus disease, but were found in $\mathbf{4 7}$ per cent of those who had experienced infection by this organism. In the latter instance, the agglutinin titer was rarely greater than 1:8. This evidence suggests that these antibodies may be maintained for a long time after the recovery from the responsible disease, since none of the studied group admitted a recent infection. The range of antistreptolysin titers in this group was approximately the same as that reported in other centers. No correlation was demonstrated between the amount of circulating agglutinin and antistreptolysin.

Twenty-four cases of scarlet fever were studied to determine the nature of the antibody response following acute infection by the Group A hemolytic streptococcus. An agglutinin response was found to occur in approximately one-half of these individuals, and usually accompanied or followed the rise in antistreptolysin titer during the sixteenth to twentieth days of the disease. Agglutinins for other types of streptococcus also appeared in several instances.

Sulfonamide medication appeared to interfere with the agglutinin response but the number of cases studied is too small for definite conclusions to be drawn.

The sera of two individuals agglutinated the infecting streptococcus at the onset of the disease. In one, the antibody was studied. It was present in high titer and was type specific. This observation indicates that, while the presence of type specific agglutinins for the hemolytic streptococcus may be an indication of the presence in the individual of antibacterial immunity, the presence of these antibodies is not sufficient to guarantee resistance to infection. Approximately 20 per cent of the total group failed to develop an increase in titer of antistreptolysin and no agglutinin response occurred in these individuals, only one of whom was not a sulfonamide-treated case.

The application of the slide agglutination test to other disease, using antigens of several types of Group A hemolytic streptococci, is in progress. It will be of interest to determine whether agglutinins are present in the sera of individuals suffering from rheumatoid arthritis and rheumatic fever, but it seems doubtful that this technique will be applicable to the routine diagnosis of any disease, since increased amounts of these antibodies are often present in the sera of normal individuals.

\section{SUMMARY}

1. Agglutinins for Group A hemolytic streptococci of various Griffith types may be demonstrated in human serum by a slide technique.

2. Such agglutinins are present in the sera of well persons and are discovered much more frequently and in higher titer in those with a past history of hemolytic streptococcus infection. 
3. An agglutinin response to the infecting type of hemolytic streptococcus, and often to other types as well, occurred in approximately 50 per cent of 24 cases of scarlet fever.

4. Suggestive evidence is presented that sulfonamide medication occasionally interfered with the development of agglutinins and antistreptolysin.

5. In 2 cases, agglutinins for the homologous type were present at the onset of the acute infection, so their presence is not an indication of antibacterial immunity.

6. The slide agglutination test may be of value in the study of rheumatic fever, rheumatoid arthritis, and also disease of known streptococcal origin.

\section{BIBLIOGRAPHY}

1. Dick, G. F., and Dick, G. H., Scarlet Fever. Yearbook Publishers, Inc., Chicago, 1938.

2. Mote, J. R., and Jones, T. D., Studies of hemolytic streptococcal antibodies in control groups, rheumatic fever and rheumatoid arthritis. I, II, and III. J. Immunol., 1941, 41, 35.

3. Lyons, $C$., Immunotransfusion and antitoxin therapy in hemolytic streptococcus infections. J. A. M. A., 1935, 105, 1972.

4. Spink, W. W., and Keefer, C. S., Studies of hemolytic streptococcal infection. II. The serological reactions of the blood during erysipelas. J. Clin. Invest., 1936, 15, 21.

5. a. Weaver, G. H., Agglutination of streptococci, especially those cultivated from cases of scarlatina, by human sera. J. Infect. Dis., 1904, 1, 91.

b. Dick, G. F., and Dick, G. R., Immune reactions in scarlet fever. J. Infect. Dis., 1916, 19, 175.

c. Sherwood, N. P., and Baumgartner, L., Studies on the Dick test and agglutination reaction in a series of university students. J. Immunol., 1926, 11, 323.

d. Smith, J., The agglutination of haemolytic streptococci by sera from cases of scarlet fever. J. Hyg., 1927, 26, 434.

e. Herrold, R. D., and Tunnicliff, R., Specific streptococcus agglutinins in concentrated scarlatinal serum. J. Infect. Dis., 1924, 34, 209.
6. a. Dawson, M. H., Olmstead, M., and Boots, R. H., Agglutination reactions in rheumatoid arthritis: I. Agglutination reactions with streptococcus hemolyticus. J. Immunol., 1932, 23, 187.

II. The nature and significance of agglutination reactions with streptococcus hemolyticus. J. Immunol., 1932, 23, 205.

b. Ferry, J. L., and Hunt, L. W., Agglutination reactions in rheumatoid arthritis. J. Lab. and Clin. Med., 1942, 27, 705.

7. Tillett, W. S., and Abernethy, T. J., Serological reactions with hemolytic streptococci in acute bacterial infections. Bull. Johns Hopkins Hosp., 1932, 50, 270.

8. Lancefield, R. C., Specific relationship of cell composition to biological activity of hemolytic streptococci. The Harvey Lectures, 1940-41, Series 36, 251.

9. Griffith, F.: The serological classification of streptococeus pyogenes. J. Hyg., 1934, 34, 542.

10. Loewenthal, $H$. ., Type specific and group specific sera against streptococci. Brit. J. Exper. Path., 1934, 15, 298.

11. Ozaki, M., The agglutinin content of placental sera for various types of group "A" streptococci. Kitasato Arch. Exper. Med., 1937, 14, 314.

12. Kodama, T., Ozaki, M., Nisiyama, S., Igarasi, J., Tiku, Y., and Kawamura, H., The serological grouping and typing of the hemolytic streptococci isolated in Tokyo. Kitasato Arch. Exper. Med., 1939, 16, 110.

13. Walker, D. W., Application of technique of slide agglutination of hemolytic streptococci to human sera. Proc. Soc. Exper. Biol. and Med., 1941, 48, 338.

14. Rantz, L. A., The serological classification of hemolytic streptococci of the Lancefield group A. J. Clin. Invest., 1942, 21, 217.

15. Coburn, A. F., and Pauli, R. H., Studies on the immune response of the rheumatic subject and its retionship to activity of the rheumatic process. I. The determination of the antistreptolysin titer. J. Exper. Med., 1935, 62, 129.

16. Rantz, L. A., The hemolytic streptococci: Studies on the carrier state in the San Francisco area with notes on the methods of isolation and serological classification of these organisms. J. Infect. Dis., 1941, 69, 248. 